Prostate cancer risk among users of digoxin and other antiarrhythmic drugs in the Finnish Prostate Cancer Screening Trial

Kaapu, K. J.

2016

Kaapu , K J , Murtola , T J , Määttänen , L, Talala , K, Taari , K, Tammela , T L J \&

Auvinen, A 2016 , ' Prostate cancer risk among users of digoxin and other antiarrhythmic drugs in the Finnish Prostate Cancer Screening Trial ' , Cancer Causes \& Control, vol. 27 , no. 2 , pp. 157-164 . https://doi.org/10.1007/s10552-015-0693-2

http://hdl.handle.net/10138/160835

https://doi.org/10.1007/s10552-015-0693-2

publishedVersion

Downloaded from Helda, University of Helsinki institutional repository.

This is an electronic reprint of the original article.

This reprint may differ from the original in pagination and typographic detail.

Please cite the original version. 


\title{
Prostate cancer risk among users of digoxin and other antiarrhythmic drugs in the Finnish Prostate Cancer Screening Trial
}

\author{
K. J. Kaapu ${ }^{1}$ T. J. Murtola ${ }^{1,2} \cdot$ L. Määttänen ${ }^{3} \cdot$ K. Talala ${ }^{3} \cdot$ K. Taari ${ }^{4}$ \\ T. L. J. Tammela ${ }^{1,2} \cdot$ A. Auvinen ${ }^{5}$
}

Received: 23 April 2015/Accepted: 31 October 2015/Published online: 16 November 2015

(C) Springer International Publishing Switzerland 2015

\begin{abstract}
Purpose Long-term usage of the antiarrhythmic drug digoxin has been connected to lowered risk of prostate cancer. A recent study has suggested that beta-blockers might also have similar risk-decreasing effects. We evaluated the association between use of digoxin, beta-blocker sotalol, and other antiarrhythmic drugs and prostate cancer risk in a retrospective cohort study.

Methods Our study population consisted of men in the Finnish Prostate Cancer Screening Trial during 1996-2012 $(n=78,615)$. During median follow-up of 12 years, 6,639 prostate cancer cases were diagnosed. The national prescription database was the source of the information of antiarrhythmic drug purchases. Data were analyzed using Cox regression method with medication use as a time-dependent variable.

Results No association was found for overall prostate cancer risk with antiarrhythmic drug use (HR 1.05 95\% CI 0.94-1.18). Neither sotalol (HR $0.9795 \%$ CI 0.76-1.24) nor digoxin (HR 1.01 95\% CI 0.87-1.16) users had a decreased risk of prostate cancer. Similar results were obtained for high-grade (Gleason 7-10) and metastatic prostate cancer.
\end{abstract}

\section{K. J. Kaapu}

kaapu.kalle.j@student.uta.fi

1 School of Medicine, University of Tampere, Medisiinarinkatu 3, 33014 Tampere, Finland

2 Department of Urology, Tampere University Hospital, Tampere, Finland

3 Finnish Cancer Registry, Helsinki, Finland

4 Department of Urology, Helsinki University Hospital, University of Helsinki, Helsinki, Finland

5 School of Health Sciences, University of Tampere, Tampere, Finland
Nevertheless, the risk estimates for Gleason 7-10 prostate cancer tended to decrease by duration of digoxin use ( $p$ for trend $=0.052$ ), suggesting that the drug may reduce the risk in long-term usage (HR 0.71, 95\% CI 0.49-1.03). In analysis stratified by screening trial arm, the protective association against Gleason 7-10 disease was observed only in the screening arm (HR $0.31,95 \%$ CI $0.12-0.84$ for men who had used digoxin for 5 years or longer).

Conclusion Digoxin or other antiarrhythmic drugs are not associated with any clear decrease in prostate cancer risk. However, digoxin might have a benefit in long-term use by reducing risk of high-grade disease. Further research will be needed to evaluate possible effects on prostate cancer survival.

Keywords Prostate cancer - Risk - Digoxin - Cohort . Antiarrhythmic drugs

\section{Introduction}

Despite being the most common cancer among men, prostate cancer etiology remains poorly understood. Even minor preventive effects would have major benefits to both public health and economics. The American Cancer Society estimates that in 2011, 240,890 men were diagnosed with prostate cancer and 33,720 men died because of the disease in the USA [1]. As little as one percent reduction in population risk of prostate cancer would mean that thousands of cancers did not occur [2].

The antiarrhythmic drug digoxin has been suggested to have prostate cancer preventive effects both by in vitro and by epidemiological studies $[3,4]$. In vitro digoxin inhibits plasma membrane $\mathrm{Na}^{+} / \mathrm{K}^{+}$-ATPase and disarrays intracellular $\mathrm{K}^{+}$and $\mathrm{Ca}^{2+}$ concentrations [4]. An increased 
$\mathrm{Ca}^{2+}$ concentration in the cell increases apoptosis [5]. In support of digoxin's beneficial effects, a large cohort study (47,884 men) recently showed decreased prostate cancer incidence among men who had used digoxin constantly for over 10 years [4] and a case-control (1,001 cases and 942 controls) study reported the prostate cancer risk was decreased in digoxin users, especially among men with 3 or more PSA tests during the past 5 years [3].

Beta-blockers are usually used for management of hypertension but sotalol, which is both a beta- and a $\mathrm{K}^{+}$channel blocker, is a common antiarrhythmic drug. It has been suggested that regular use of beta-blockers is associated with decreased risk of cancer [6]. We have previously shown that sotalol users may have lowered prostate cancer risk [7].

We analyzed how use of digoxin, sotalol, or other antiarrhythmic drugs is linked with overall prostate cancer risk and with tumor characteristics at diagnosis in a cohort of men participating in the Finnish Prostate Cancer Screening Trial.

\section{Materials and methods}

\section{Study population}

The study cohort consisted of men randomized to the Finnish Prostate Cancer Screening Trial (FinRSPC) during 1996-1999 and followed up until the end of 2012. The FinRSPC protocol has been previously described in detail [8]. In brief, 80,456 men aged 55-67 years and living in the metropolitan areas of Tampere and Helsinki, Finland, were identified from the Population Register Center and randomized either to be screened for prostate cancer with PSA test at 4-year intervals $(31,866$ men, the screening arm) or to be followed through the national Finnish Cancer Registry (48,278 men, the control arm).

Information on prostate cancers cases diagnosed in the study population included information on tumor Gleason grade at diagnosis, TNM stage, serum PSA value (for the screening arm), and the date and method of diagnosis.

Prostate cancer was diagnosed in 6,639 men of the study population before 2010. The method of detection was known for 6,082 cases (91.6\%). Of these, 2,584 (42.5\%) were detected through screening, 1,938 (31.9\%) between the screening rounds, $327(5.4 \%)$ in men invited to screening but not participating and $29(0.5 \%)$ in autopsy. Most cases were histologically confirmed $(98.1 \%)$. Other methods of diagnostic verification included clinical $(0.3 \%)$ and at autopsy (1.6\%). One case was only radiologically and one cytologically confirmed. The method of diagnosis was unknown in three cases.
The study was approved by the ethics committee of the Pirkanmaa health care district, Finland (tracking number ETL 95077).

\section{Information on medication use}

Data of refunded physician-prescribed medication purchases for the entire cohort during 1995-2009 were collected from the nationwide prescription database of the Social Insurance Institution (SII) of Finland. SII provides reimbursements for the costs of medicine prescribed by a physician for all Finnish residents [9]. Every reimbursed purchase of a prescribed drug is registered in the database. The information in the registry includes date for each purchase, number of packages obtained, as well as the number and dosage of pills.

Information on drugs categorized as antiarrhythmic in Pharmaca Fennica, the Finnish national pharmaceutical guide, was collected: amiodarone, digoxin, disopyramide, etilefrine, flecainide, quinidine, mexiletine, procainamide, propafenone, and sotalol. All drugs were available for every year of the study follow-up except etilefrine (1995-2008) and procainamide (only 1995). The purchases of most drugs reduced significantly over time. For example, 6,110 men bought digoxin in 1997 but only 1,815 in 2009. Only purchases of flecainide increased from 92 (in 1995) to 473 (in 2009) during the study. Purchases of amiodarone and propafenone remained constant. Information on medication use was available for 78,615 men ( $98.1 \%$ of the entire screening trial population).

\section{Statistical analysis}

We used Cox regression method to analyze prostate cancer risk overall, as well as by stage and Gleason grade. We performed age-adjusted and multivariable analyses (further adjustment for use of other drug groups: NSAIDs, aspirin, antidiabetic medication, statins, antihypertensives, 5alphareductase inhibitors, and alpha-blockers). Multivariableadjusted risk estimates are reported unless otherwise stated. We analyzed class effect of antiarrhythmic drugs by comparing users of any antiarrhythmic drugs to non-users. Drug-specific effects were separately analyzed for digoxin and sotalol. Men who had used both drug groups were included in both analyses. Sensitivity analyses with further adjustment for digoxin or sotalol usage were performed to adjust for simultaneous usage.

Medication use status was updated prospectively each year of follow-up based on yearly medication purchases. Men with recorded purchases at any given year were regarded as users for that year. Users with a full year without purchases changed status into previous users. The status was allowed to change back to users if drug 
purchases were resumed at later point of follow-up. Never users and all users before the first purchase were classified as non-users. Non-users were used as the reference group in all analyses.

The amount of antiarrhythmic drug use was standardized by dividing the yearly $\mathrm{mg}$ amount of each drug with the standard defined daily dose (DDD) published in public WHO website [10]. Duration of usage was calculated as number of years with medication purchases. Intensity of use (DDDs/year) was calculated by dividing the yearly cumulative amount with the number of years of usage. In men who stopped previous usage before the end of followup, the cumulative amount, duration, and intensity of use remained at the level reached before discontinuation.

Cumulative amount (DDDs), duration (years), and intensity (DDDs/year) of medication use were also updated prospectively according to the yearly purchases. Men discontinuing previous use retained the level reached before the discontinuation. Trends in prostate cancer risk by amount, duration, and intensity of the medication use were evaluated by stratifying the cohort by tertiles and repeating the analysis for each stratum. Additionally, we analyzed the trends by adding the cumulative amount/duration/intensity of use as a continuous variable into the Cox regression model. These analyses were necessary to estimate the association between prostate cancer risk and longterm drug usage, which was linked with reduced risk in the previous study [3].

Subgroup analyses were performed by stratifying the population by baseline characteristics, screening trial arm, and usage of other drug groups. We estimated effect modification by these variables on prostate cancer risk among antiarrhythmic medication users by adding interaction term with medication use into the Cox regression model. Furthermore, we estimated the effect of confounding by indication comparing digoxin users to men using other types of antiarrhythmic drugs or antihypertensive drugs.

We used $\chi^{2}$-test to estimate the statistical significance of differences in population characteristics by antiarrhythmic drug use.

All statistical tests are two-sided; $p$ values 0.05 or less were considered statistically significant. IBM SPSS Statistics 22 (Chicago, IL, USA) software was used for data analyses.

\section{Results}

\section{Population characteristics}

The overall prevalence of antiarrhythmic drug use was $10.3 \%$ (8,064 men). The prevalence of digoxin use was
$7.2 \%$ (5,668 men) and for sotalol $3.2 \%$ (2,540 men). Median age at baseline among never users of antiarrhythmic drugs was 59 years. Among users the median age was slightly greater, 63 years. A similar difference was observed between ever and never users of digoxin and sotalol. No differences were observed in baseline PSA levels by antiarrhythmic drug use (Table 1).

During the median follow-up of 12 years, 6,639 prostate cancer cases were diagnosed within the cohort. Compared to non-users of antiarrhythmic drugs, the users had lower cumulative incidence of high-grade (Gleason 7-10) tumors (42.2 vs. $39.2 \%)$ and metastatic disease at diagnosis (6.29 vs. $5.89 \%$, respectively) (Table 1). The incidence of highgrade disease was also slightly lower among users of digoxin (40.8 vs. $39.2 \%$ in non-users and users, respectively) and sotalol (41.9 vs. $40.2 \%$ ).

The usage of other drug groups (NSAIDs, aspirin, 5alfareductase inhibitors, alpha-blockers, antihypertensive drugs, antidiabetic drugs, and statins) was more frequent among antiarrhythmic drug users compared to the nonusers (Table 1).

\section{Antiarrhythmic drugs in general and prostate cancer}

Overall prostate cancer risk was slightly elevated among current antiarrhythmic drug users compared to non-users in the age-adjusted analysis, but not in the multivariable-adjusted analysis (Table 2). No significant association was observed for risk of either high-grade or metastatic prostate cancer.

The overall prostate cancer risk increased slightly by cumulative amount and intensity of antiarrhythmic drug use, although the trend was not significant (Table 3). This trend, however, was not observed for high-grade cancer. For metastatic cancer, the risk was elevated at the beginning of usage, i.e., men whose cumulative amount was lowest, but not with continued use.

\section{Digoxin use and prostate cancer}

Overall, digoxin use was not associated with prostate cancer risk or with tumor grade or stage (Table 2). However, the association between digoxin use and prostate cancer was modified by prostate cancer screening; digoxin users had a borderline significantly decreased prostate cancer risk in the screening arm (HR 0.82, 95\% CI 0.64-1.04) but not in the control arm ( $p$ for interaction $=0.052)($ Table 2).

Risk estimates for high-grade and metastatic prostate cancer tended to decrease with increasing amount and duration of digoxin use (Table 3), but remained statistically non-significant. A borderline significant decrease in the 
Table 1 Population characteristics

\begin{tabular}{|c|c|c|c|c|c|c|c|c|c|}
\hline & \multicolumn{3}{|c|}{ Use of antiarrhythmic drugs } & \multicolumn{3}{|l|}{ Use of digoxin } & \multicolumn{3}{|l|}{ Use of sotalol } \\
\hline & Never & Ever & $p$ value & Never & Ever & $p$ value & Never & Ever & $p$ value \\
\hline No. of cases & 5,807 & 730 & & 6,052 & 485 & & 6,296 & 241 & \\
\hline $\begin{array}{l}\text { Gleason } 6 \text { or less } \\
\text { tumor }\end{array}$ & $\begin{array}{l}3,203 \\
\quad(55.1 \%)\end{array}$ & $\begin{array}{l}419 \\
\quad(57.4 \%)\end{array}$ & & $\begin{array}{l}3,343 \\
\quad(55.3 \%)\end{array}$ & $\begin{array}{l}279 \\
\quad(57.5 \%)\end{array}$ & & $\begin{array}{l}3,488 \\
\quad(55.4 \%)\end{array}$ & $\begin{array}{l}134 \\
\quad(55.6 \%)\end{array}$ & \\
\hline Gleason 7-10 & $\begin{array}{l}2,450 \\
\quad(42.2 \%)\end{array}$ & $\begin{array}{l}286 \\
\quad(39.2 \%)\end{array}$ & & $\begin{array}{l}2,456 \\
\quad(40.8 \%)\end{array}$ & $\begin{array}{l}190 \\
(39.2 \%)\end{array}$ & & $\begin{array}{l}2,639 \\
\quad(41.9 \%)\end{array}$ & $97(40.2 \%)$ & \\
\hline Metastatic cases & $365(6.29 \%)$ & $43(5.89 \%)$ & & $376(6.21 \%)$ & $32(6.60 \%)$ & & $392(6.23 \%)$ & $16(6.64 \%)$ & \\
\hline $\begin{array}{l}\text { Median PSA-level (ng/ } \\
\text { ml) }\end{array}$ & 1.07 & 1.07 & 0.49 & 1.07 & 1.08 & 0.59 & 1.08 & 1.01 & 0.28 \\
\hline \multicolumn{10}{|l|}{ Use of other drugs } \\
\hline NSAIDs & $\begin{array}{l}55,664 \\
\quad(78.9 \%)\end{array}$ & $\begin{array}{l}6,609 \\
\quad(82.0 \%)\end{array}$ & 0.001 & $\begin{array}{l}57,722 \\
\quad(79.1 \%)\end{array}$ & $\begin{array}{l}4,551 \\
\quad(80.3 \%)\end{array}$ & 0.039 & $\begin{array}{l}60,131 \\
\quad(79.0 \%)\end{array}$ & $\begin{array}{l}2,142 \\
\quad(84.3 \%)\end{array}$ & 0.001 \\
\hline Aspirin & $\begin{array}{l}10,894 \\
\quad(15.4 \%)\end{array}$ & $\begin{array}{l}1,485 \\
\quad(18.4 \%)\end{array}$ & 0.001 & $\begin{array}{l}11,409 \\
\quad(15.6 \%)\end{array}$ & $\begin{array}{l}970 \\
\quad(17.1 \%)\end{array}$ & 0.004 & $\begin{array}{l}11,832 \\
\quad(15.6 \%)\end{array}$ & $\begin{array}{l}547 \\
\quad(21.5 \%)\end{array}$ & 0.001 \\
\hline Statins & $\begin{array}{l}28,526 \\
\quad(40.4 \%)\end{array}$ & $\begin{array}{l}4,238 \\
\quad(53.7 \%)\end{array}$ & 0.001 & $\begin{array}{l}29,905 \\
\quad(41.0 \%)\end{array}$ & $\begin{array}{l}2,949 \\
\quad(52.0 \%)\end{array}$ & 0.001 & $\begin{array}{l}31,339 \\
\quad(41.2 \%)\end{array}$ & $\begin{array}{l}1,515 \\
\quad(59.6 \%)\end{array}$ & 0.001 \\
\hline Antidiabetic drugs & $\begin{array}{l}13,453 \\
(19.1 \%)\end{array}$ & $\begin{array}{l}2,440 \\
\quad(30.3 \%)\end{array}$ & 0.001 & $\begin{array}{l}13,979 \\
(19.2 \%)\end{array}$ & $\begin{array}{l}1,914 \\
(33.8 \%)\end{array}$ & 0.001 & $\begin{array}{l}15,177 \\
(20.0 \%)\end{array}$ & $\begin{array}{l}716 \\
(28.2 \%)\end{array}$ & 0.001 \\
\hline Antihypertensives & $\begin{array}{l}45,183 \\
\quad(64.0 \%)\end{array}$ & $\begin{array}{l}7,748 \\
\quad(96.1 \%)\end{array}$ & 0.001 & $\begin{array}{l}47,372 \\
\quad(64.9 \%)\end{array}$ & $\begin{array}{l}5,559 \\
\quad(98.1 \%)\end{array}$ & 0.001 & $\begin{array}{l}50,489 \\
\quad(66.4 \%)\end{array}$ & $\begin{array}{l}2,442 \\
\quad(96.1 \%)\end{array}$ & 0.001 \\
\hline $\begin{array}{l}\text { 5alpha-reductase } \\
\text { inhibitors }\end{array}$ & $\begin{array}{l}8,538 \\
\quad(12.1 \%)\end{array}$ & $\begin{array}{l}1,148 \\
\quad(14.2 \%)\end{array}$ & 0.001 & $\begin{array}{l}8,946 \\
\quad(12.3 \%)\end{array}$ & $\begin{array}{l}740 \\
\quad(13.1 \%)\end{array}$ & 0.081 & $\begin{array}{l}9,299 \\
\quad(12.2 \%)\end{array}$ & $\begin{array}{l}387 \\
\quad(15.2 \%)\end{array}$ & 0.001 \\
\hline Alpha-blockers & $\begin{array}{l}18,776 \\
(26.6 \%)\end{array}$ & $\begin{array}{l}2,567 \\
(31.8 \%)\end{array}$ & 0.001 & $\begin{array}{l}19,643 \\
(26.9 \%)\end{array}$ & $\begin{array}{l}1,700 \\
(30.0 \%)\end{array}$ & 0.001 & $\begin{array}{l}20,491 \\
\quad(26.9 \%)\end{array}$ & $\begin{array}{l}852 \\
\quad(33.5 \%)\end{array}$ & 0.001 \\
\hline
\end{tabular}

risk of high-grade prostate cancer was observed among men who used digoxin for 6 years or longer (HR 0.71, 95\% CI 0.49-1.03). A similar decrease in the risk estimate was also observed for metastatic disease in long-term users (HR $0.80,95 \%$ CI $0.30-2.16)$. No clear trends in risk estimates were observed for intensity of digoxin use.

Among men in the screening arm, a significant risk reduction for Gleason 7-10 prostate cancer was observed for men who have used digoxin for longer than 5 years (HR 0.31, 95\% CI 0.12-0.84). Antiarrhythmic drug use in general among the same sub-cohort (screening arm, longer than 5 years of drug usage) was not associated with significant risk reduction (HR 0.64, 95\% CI 0.40-1.02).

\section{Sotalol use and prostate cancer}

No risk association was observed with sotalol use for overall, high-grade, and metastasized prostate cancer risks (Table 2).

The amount of sotalol usage was not associated with overall or high-grade prostate cancer risk. No significant risk difference was observed for metastatic disease, either (Table 3).

\section{Subgroup analyses}

Age at randomization modified the association between antiarrhythmic drugs and prostate cancer risk; the risk was lower in men aged 55-59 years at baseline ( $p$ for interaction $=0.001)$. The overall prostate cancer risk was decreased among 55- to 59-year-old current sotalol user compared to non-users; HR 0.54 , 95\% CI 0.30-0.97. This difference was not seen in the older age group ( $p$ for interaction $=0.006)$ (Table 4).

Prostate cancer risk in digoxin users did not differ from men using other types of antiarrhythmic drugs in a sensitivity analysis limited to drug users only (HR 0.96, 95\% CI 0.81-1.15). No risk difference was observed for high-grade or metastatic disease, either. Further, digoxin use was not associated with prostate cancer risk in analysis with antihypertensive drug users as the comparison group (HR 1.00, 95\% CI 0.86-1.16).

Use of other medications did not modify the effect of antiarrhythmic drugs (Table 4). The sensitivity analyses to estimate the effect of simultaneous usage of digoxin and sotalol did not show any differences in prostate cancer risk estimates. 
Table 2 Prostate cancer risk, overall, and by grade and stage in antiarrhythmic drug users

\begin{tabular}{|c|c|c|c|c|c|}
\hline \multirow[t]{2}{*}{ Overall risk } & \multirow[t]{2}{*}{$n$} & \multicolumn{2}{|c|}{ All FinPCST participants } & \multirow{2}{*}{$\begin{array}{l}\text { Screening arm } \\
\text { Multivariable-adjusted } \\
\text { analysis }{ }^{\mathrm{a}, \mathrm{b}} \\
\text { HR }(95 \% \mathrm{CI})\end{array}$} & \multirow{2}{*}{$\begin{array}{l}\text { Control arm } \\
\text { Multivariable-adjusted } \\
\text { analysis }{ }^{\mathrm{a}, \mathrm{b}} \\
\text { HR }(95 \% \mathrm{CI})\end{array}$} \\
\hline & & $\begin{array}{l}\text { Age-adjusted } \\
\text { analysis } \\
\text { HR }(95 \% \mathrm{CI})\end{array}$ & $\begin{array}{l}\text { Multivariable-adjusted } \\
\text { analysis }^{\mathrm{a}} \\
\text { HR }(95 \% \mathrm{CI})\end{array}$ & & \\
\hline \multicolumn{6}{|c|}{ All antiarrhythmic drugs } \\
\hline Users & 319 & $1.13(1.01-1.27)$ & $1.05(0.94-1.18)$ & $0.97(0.81-1.16)$ & $1.09(0.94-1.26)$ \\
\hline Previous users & 197 & $1.08(0.93-1.26)$ & $1.00(0.86-1.17)$ & $1.00(0.78-1.28)$ & $0.99(0.81-1.21)$ \\
\hline \multicolumn{6}{|l|}{ Digoxin } \\
\hline Users & 191 & $1.06(0.92-1.23)$ & $1.01(0.87-1.16)$ & $0.82(0.64-1.04)$ & $1.13(0.94-1.35)$ \\
\hline Previous users & 135 & $1.09(0.90-1.31)$ & $1.03(0.85-1.24)$ & $1.08(0.81-1.43)$ & $0.97(0.76-1.25)$ \\
\hline \multicolumn{6}{|l|}{ Sotalol } \\
\hline Users & 63 & $1.05(0.82-1.34)$ & $0.97(0.76-1.24)$ & $0.88(0.60-1.30)$ & $1.05(0.76-1.45)$ \\
\hline Previous users & 129 & $1.16(0.96-1.41)$ & $1.07(0.88-1.29)$ & $1.13(0.84-1.54)$ & $1.02(0.80-1.30)$ \\
\hline \multicolumn{6}{|c|}{ Gleason $7-10$ prostate cancer risk } \\
\hline \multicolumn{6}{|c|}{ All antiarrhythmic drugs } \\
\hline Users & 118 & $0.99(0.82-1.19)$ & $0.90(0.74-1.08)$ & $0.92(0.67-1.25)$ & $0.88(0.70-1.11)$ \\
\hline Previous users & 100 & $1.17(0.95-1.44)$ & $1.06(0.86-1.31)$ & $1.23(0.87-1.74)$ & $0.97(0.74-1.26)$ \\
\hline \multicolumn{6}{|l|}{ Digoxin } \\
\hline Users & 73 & $0.94(0.75-1.19)$ & $0.87(0.69-1.10)$ & $0.67(0.43-1.04)$ & $0.97(0.73-1.27)$ \\
\hline Previous users & 66 & $1.12(0.86-1.46)$ & $1.04(0.80-1.35)$ & $1.28(0.85-1.93)$ & $0.91(0.64-1.29)$ \\
\hline \multicolumn{6}{|l|}{ Sotalol } \\
\hline Users & 25 & $1.11(0.75-1.65)$ & $1.03(0.69-1.52)$ & $1.25(0.69-2.26)$ & $0.91(0.54-1.54)$ \\
\hline Previous users & 57 & $1.10(0.83-1.46)$ & $1.00(0.75-1.33)$ & $1.40(0.90-2.16)$ & $0.81(0.56-1.18)$ \\
\hline \multicolumn{6}{|c|}{ Metastatic prostate cancer risk ${ }^{\mathrm{c}}$} \\
\hline \multicolumn{6}{|c|}{ All antiarrhythmic drugs } \\
\hline Users & 24 & $1.33(0.88-2.01)$ & $1.21(0.80-1.83)$ & $1.48(0.71-3.07)$ & $1.10(0.66-1.84)$ \\
\hline Previous users & 12 & $1.03(0.55-1.93)$ & $0.94(0.50-1.77)$ & $0.74(0.18-3.02)$ & $1.00(0.49-2.03)$ \\
\hline \multicolumn{6}{|l|}{ Digoxin } \\
\hline Users & 15 & $1.29(0.77-2.16)$ & $1.14(0.68-1.92)$ & $1.06(0.39-2.90)$ & $1.18(0.64-2.16)$ \\
\hline Previous users & 11 & $1.39(0.72-2.70)$ & $1.25(0.64-2.44)$ & $1.02(0.25-4.18)$ & $1.34(0.63-2.85)$ \\
\hline \multicolumn{6}{|l|}{ Sotalol } \\
\hline Users & 6 & $1.55(0.69-3.46)$ & $1.49(0.67-3.35)$ & $1.83(0.45-7.43)$ & $1.36(0.50-3.65)$ \\
\hline Previous users & 5 & $0.87(0.36-2.11)$ & $0.83(0.34-2.01)$ & $2.23(0.70-7.10)$ & $0.42(0.10-1.68)$ \\
\hline
\end{tabular}

${ }^{a}$ From Cox regression model adjusted for age, screening trial arm and use of cholesterol-lowering, antidiabetic and antihypertensive drugs, aspirin and other NSAIDs, and 5alpha-reductase inhibitors and alpha-blockers

${ }^{\mathrm{b}} p$ for interaction in risk of prostate cancer among digoxin users by FinPCST study arm $=0.052$

c Stage M1 at diagnosis

\section{Discussion}

We did not find a clear association between antiarrhythmic drug usage and prostate cancer risk. Similarly, neither usage of digoxin nor sotalol had an influence on the risk. Nonetheless, the risk estimates for high-grade and metastatic prostate cancer tended to decrease by increasing cumulative amount and duration of digoxin use. However, a similar decreasing trend was observed also for antiarrhythmic drugs in general and could thus be due to systematic differences between users and non-users of this drug group rather than due to digoxin usage. However, the risk reduction for Gleason 7-10 cancer in the screening arm was observed only for long-term users of digoxin. Thus, our results lend some support for oncological benefits of long-term digoxin use, as previously reported by Platz et al. [3] in a case-control study.

We must consider the possibility that the observed risk associations result from confounding by indication. When digoxin users were compared to other antiarrhythmic drug 


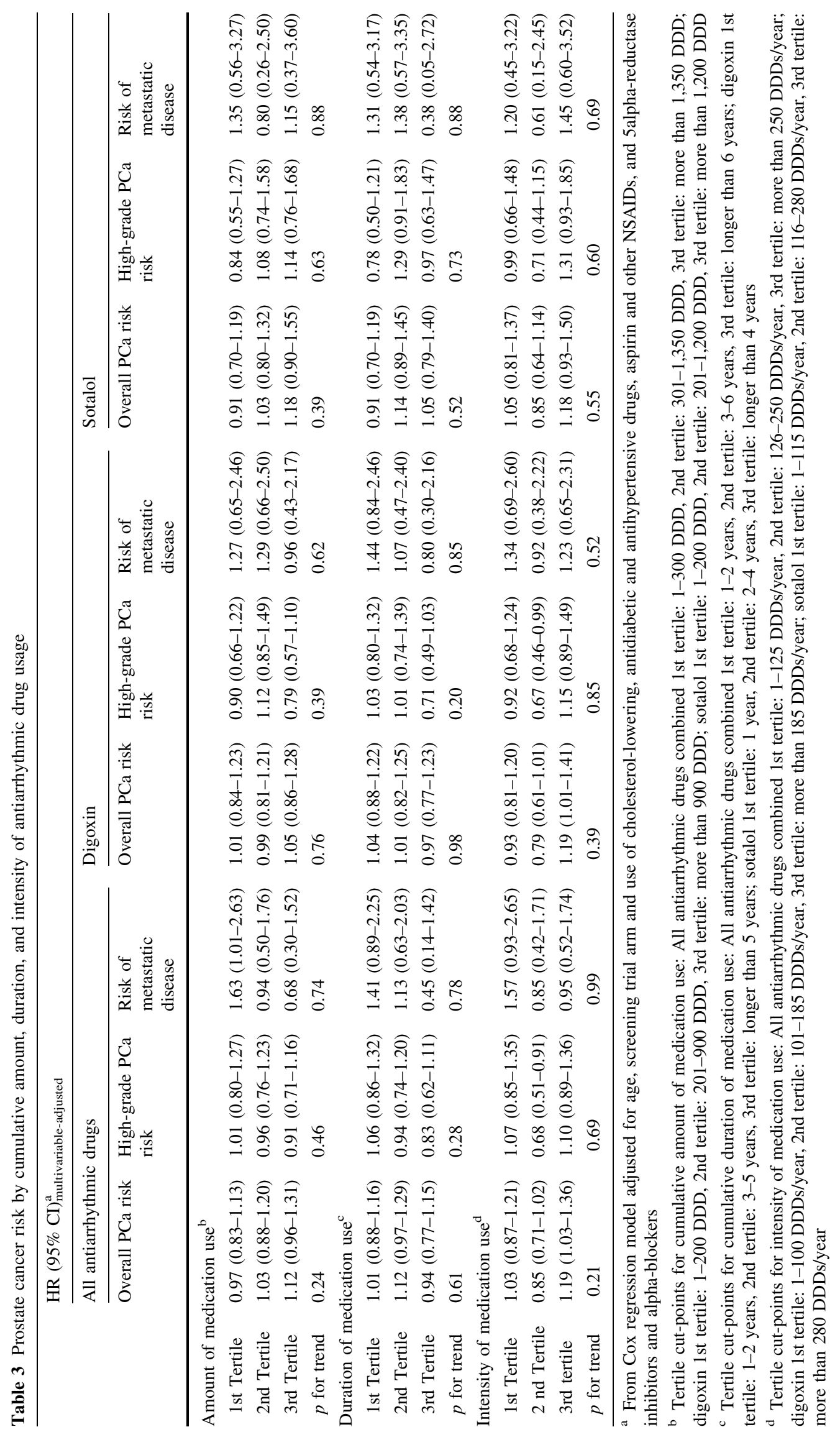


Table 4 Prostate cancer risk by antiarrhythmic drug usage in subgroups stratified by baseline variables

\begin{tabular}{|c|c|c|c|}
\hline & \multicolumn{3}{|c|}{ HR $(95 \% \mathrm{CI})_{\text {multivariable-adjusted }}^{\mathrm{a}}$} \\
\hline & All Antiarrhythmic drugs & Digoxin & Sotalol \\
\hline \multicolumn{4}{|c|}{ Age at randomization } \\
\hline $55-59$ & $0.84(0.68-1.04)$ & $0.90(0.68-1.18)$ & $0.54(0.30-0.97)$ \\
\hline $63-67$ & $1.09(0.95-1.25)$ & $0.99(0.84-1.18)$ & $1.08(0.82-1.41)$ \\
\hline$p$ for interaction & 0.001 & 0.143 & 0.006 \\
\hline \multicolumn{4}{|c|}{ Antiarrhythmic drug use before randomization } \\
\hline No & $0.96(0.81-1.13)$ & $0.93(0.75-1.15)$ & $0.99(0.70-1.40)$ \\
\hline Yes & $1.11(0.79-1.55)$ & $0.96(0.73-1.25)$ & $0.87(0.59-1.28)$ \\
\hline$p$ for interaction & 0.42 & 0.72 & 0.65 \\
\hline \multicolumn{4}{|l|}{ NSAID usage } \\
\hline Non-users & $1.26(0.95-1.68)$ & $1.19(0.84-1.69)$ & $1.40(0.75-2.62)$ \\
\hline Users & $1.02(0.90-1.15)$ & $0.97(0.83-1.14)$ & $0.92(0.70-1.21)$ \\
\hline$p$ for interaction & 0.843 & 0.474 & 0.401 \\
\hline \multicolumn{4}{|l|}{ ASA usage } \\
\hline Non-users & $1.08(0.96-1.22)$ & $1.04(0.89-1.21)$ & $0.92(0.69-1.22)$ \\
\hline Users & $0.91(0.66-1.24)$ & $0.83(0.54-1.27)$ & $1.26(0.74-2.13)$ \\
\hline$p$ for interaction & 0.820 & 0.468 & 0.222 \\
\hline \multicolumn{4}{|c|}{ Antidiabetic drug usage } \\
\hline Non-users & $1.06(0.93-1.22)$ & $1.00(0.83-1.20)$ & $1.00(0.75-1.32)$ \\
\hline Users & $1.02(0.82-1.25)$ & $1.02(0.80-1.30)$ & $0.89(0.54-1.48)$ \\
\hline$p$ for interaction & 0.155 & 0.446 & 0.434 \\
\hline \multicolumn{4}{|l|}{ Statin usage } \\
\hline Non-users & $1.13(0.95-1.33)$ & $1.11(0.90-1.36)$ & $0.95(0.67-1.43)$ \\
\hline Users & $1.00(0.86-1.17)$ & $0.93(0.76-1.14)$ & $0.98(0.71-1.34)$ \\
\hline$p$ for interaction & 0.687 & 0.555 & 0.880 \\
\hline \multicolumn{4}{|c|}{ Antihypertensive drug usage } \\
\hline Non-users & $1.13(0.61-2.11)$ & $1.34(0.50-3.58)$ & $0.51(0.13-2.03)$ \\
\hline Users & $1.05(0.94-1.18)$ & $1.00(0.86-1.16)$ & $1.00(0.78-1.29)$ \\
\hline$p$ for interaction & 0.222 & 0.883 & 0.528 \\
\hline \multicolumn{4}{|c|}{ 5alpha-reductase inhibitor usage } \\
\hline Non-users & $1.04(0.92-1.18)$ & $1.00(0.85-1.17)$ & $0.96(0.74-1.26)$ \\
\hline Users & $1.07(0.80-1.43)$ & $1.05(0.71-1.54)$ & $0.97(0.50-1.87)$ \\
\hline$p$ for interaction & 0.958 & 0.878 & 0.584 \\
\hline \multicolumn{4}{|l|}{ Alpha-blocker usage } \\
\hline Non-users & $1.05(0.90-1.24)$ & $0.95(0.77-1.17)$ & $1.04(0.74-1.45)$ \\
\hline Users & $1.03(0.88-1.20)$ & $1.04(0.85-1.27)$ & $0.91(0.63-1.31)$ \\
\hline$p$ for interaction & 0.750 & 0.765 & 0.275 \\
\hline
\end{tabular}

${ }^{a}$ From Cox regression model adjusted for age, screening trial arm and use of cholesterol-lowering, antidiabetic and antihypertensive drugs, aspirin and other NSAIDs, and 5alpha-reductase inhibitors and alpha-blockers users, i.e., within the group supposedly having similar indications for drug usage, no protective risk differences were observed.

Besides being used in treatment of atrial fibrillation, digoxin is also used in management of congestive heart failure. Antihypertensive drugs are also commonly used in heart failure patients. However, no risk association was found when digoxin users were compared to these antihypertensive drug users.

The Health Professionals Follow-up study demonstrated that long-term digoxin users ( $>10$ years) had a lowered prostate cancer risk (RR $0.5495 \%$ CI $0.37-0.79$, $p$ trend $<0.001)$ [4]. Our study cohort was larger $(78,615$ vs. $47,884)$ with more prostate cancer diagnoses $(6,639$ vs. 
$5,002)$ and more digoxin users (485 vs. 243 ). In the previous study, only 28 men had used digoxin over 10 years. We categorized the use of 6 years or more as long-term usage. Our study population consisted of 305 long-term users and 175 men who have used digoxin for over 10 years. Therefore, our study had greater statistical power to study the long-term effects of these drugs. It should be noted that we observed a protective risk association for long-term digoxin use only among men under prostate cancer screening, not in the control arm. Due to widespread PSA testing in the USA, participants of the Health Professionals Follow-up study were likely in regular PSA surveillance. Thus, our results are in concordance with this previous study.

Our study cohort also has some similarities to the Health Professionals study. At the beginning of the follow-up, participants were 40-75 years old in the US study, whereas the age of our study population was 55-67 at the start of the follow-up. Both cohorts consisted mostly of Caucasians, so ethnicity is unlikely to be a confounding factor.

Our study has some strengths. Our information on medication use was comprehensive with minimal misclassification; a possible recall bias is excluded in our study as medication purchases are recorded by the database regardless of cancer status. Another important strength of our study is the large study population consisting of men living in two metropolitan areas in Finland. The study cohort was large enough to analyze the influence of an uncommonly used drug, such as digoxin, on the risk of prostate cancer, even by disease grade and stage. In comparison with the previous US study, our information on medication use was not collected from surveys but from objectively recorded national registry data.

Some limitations should be considered. First, from the nationwide prescription database of the SII of Finland we were able to obtain the purchase information of any reimbursed drugs. Conversely, the exact indication for the purchases of the antiarrhythmic drugs was not available and thus we were not able to control for indication of drug usage in our analysis. However, evidence linking cardiac arrhythmias to prostate cancer risk is sparse. We were able control for underlying diseases indirectly by adjusting for the usage of other drug groups.

Second, we had no information on lifestyle factors. Previous studies have showed that factors such as exercise, BMI, smoking, and diet might have an impact on the risk of prostate cancer [11]. These could have caused confounding in either direction depending on their distribution between the users and non-users of the antiarrhythmic drugs.

Third, we did not have information about whether the received drugs were actually used. This might have caused exposure misclassification and bias toward the null.

\section{Conclusion}

In conclusion, neither antiarrhythmic drug usage in general, nor digoxin or sotalol usage impacted the overall risk of prostate cancer. Nonetheless, our study does lend some support for the protective effect of long-term usage of digoxin, as the risk estimates for high-grade (Gleason score 7-10) cancer tended to decrease as the cumulative years of digoxin use increase. This effect was more distinct among men in the screening arm. Further studies should address whether or not digoxin use affects prostate cancer mortality.

Funding This work was supported by research grants from the Finnish Cultural Foundation and Pirkanmaa Hospital District to T.J. Murtola.

\section{Compliance with ethical standards}

Conflicts of interest T.J. Murtola: Lecture fee from Janssen-Cilag and MSD, K. Taari: Paid consultant for Astellas, GSK, Amgen, Pfizer, Sanofi, Janssen-Cilag, employee of Medication Inc, T.L.J. Tammela: Paid consultant for Astellas, GSK, Pfizer, Orion Pharma and Amgen. All remaining authors have declared no conflicts of interest.

\section{References}

1. Brawley OW (2012) Prostate cancer epidemiology in the United States. World J Urol 30:195-200

2. Hsing AW, Chokkalingam AP (2006) Prostate cancer epidemiology. Front Biosci 11:1388-1413

3. Wright JL, Hansten PD, Stanford JL (2014) Is digoxin use for cardiovascular disease associated with risk of prostate cancer? Prostate 74:97-102

4. Platz EA, Yegnasubramanian S, Liu JO et al (2011) A novel twostage, transdisciplinary study identifies digoxin as a possible drug for prostate cancer treatment. Cancer Discov 1:68-77

5. Prevarskaya N, Skryma R, Shuba Y (2004) $\mathrm{Ca}^{2+}$ homeostasis in apoptotic resistance of prostate cancer cells. Biochem Biophys Res Commun 322:1326-1335

6. Monami M, Filippi L, Ungar A et al (2013) Further data on betablockers and cancer risk: observational study and meta-analysis of randomized clinical trials. Curr Med Res Opin 29:369-378

7. Kaapu KJ, Ahti J, Tammela TL, Murtola TJ (2015) Sotalol, but not digoxin is associated with decreased prostate cancer risk: a population-based case-control study. Int J Cancer. doi:10.1002/ ijc. 29470

8. Kilpeläinen TP, Tammela TL, Malila N et al (2013) Prostate cancer mortality in the Finnish randomized screening trial. J Natl Cancer Inst 105:719-725

9. Hemminki E, Bomann-Larsen P (1981) Drug reimbursement in four Nordic countries. Scand J Public Health 9:1-10

10. WHO Collaborating Centre for Drug Statistics Methodology. (2013) ATC/DDD Index 2013. http://www.whocc.no/atc_ddd_ index/

11. Wilson KM, Giovannucci EL, Mucci LA (2012) Lifestyle and dietary factors in the prevention of lethal prostate cancer. Asian J Androl 14:365-374 